This Health Hazard Evaluation (HHE) report and any recommendations made herein are for the specific facility evaluated and may not be universally applicable. Any recommendations made are not to be considered as final statements of NIOSH policy or of any agency or individual involved. Additional HHE reports are available at http://www.cdc.gov/niosh/hhe/reports

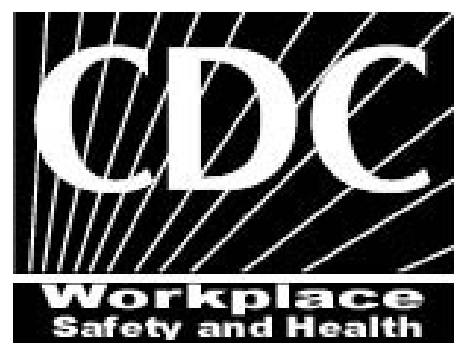

NIOSH HEALTH HAZARD EVALUATION REPORT:

HETA \#2002-0155-2886

DaimlerChrysler Indiana Transmission Plant Kokomo, Indiana

\title{
December 2002
}

DEPARTMENT OF HEALTH AND HUMAN SERVICES Centers for Disease Control and Prevention National Institute for Occupational Safety and Health

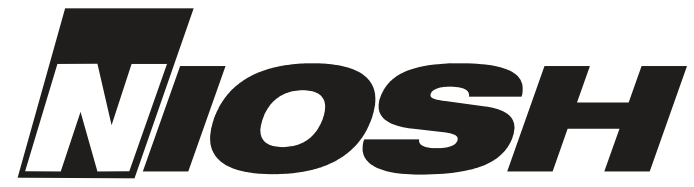




\title{
PREFACE
}

The Hazard Evaluations and Technical Assistance Branch (HETAB) of the National Institute for Occupational Safety and Health (NIOSH) conducts field investigations of possible health hazards in the workplace. These investigations are conducted under the authority of Section 20(a)(6) of the Occupational Safety and Health (OSHA) Act of 1970, 29 U.S.C. 669(a)(6) which authorizes the Secretary of Health and Human Services, following a written request from any employer or authorized representative of employees, to determine whether any substance normally found in the place of employment has potentially toxic effects in such concentrations as used or found.

HETAB also provides, upon request, technical and consultative assistance to Federal, State, and local agencies; labor; industry; and other groups or individuals to control occupational health hazards and to prevent related trauma and disease. Mention of company names or products does not constitute endorsement by NIOSH.

\section{ACKNOWLEDGMENTS AND AVAILABILITY OF REPORT}

This report was prepared by Douglas Trout, MD, MHS, and Joshua Harney, MS, of HETAB, Division of Surveillance, Hazard Evaluations and Field Studies (DSHEFS). Field assistance was provided by Barbara MacKenzie and Debbie Sammons. Analytical support was provided by David Weissman, Daniel Lewis, and Ronald Kovein. Desktop publishing was performed by Patricia McGraw. Review and preparation for printing were performed by Penny Arthur.

Copies of this report have been sent to employee and management representatives at ITP and the OSHA Regional Office. This report is not copyrighted and may be freely reproduced. Single copies of this report will be available for a period of three years from the date of this report. To expedite your request, include a self-addressed mailing label along with your written request to:

\author{
NIOSH Publications Office \\ 4676 Columbia Parkway \\ Cincinnati, Ohio 45226 \\ 800-356-4674
}

After this time, copies may be purchased from the National Technical Information Service (NTIS) at 5825 Port Royal Road, Springfield, Virginia 22161. Information regarding the NTIS stock number may be obtained from the NIOSH Publications Office at the Cincinnati address.

For the purpose of informing affected employees, copies of this report shall be posted by the employer in a prominent place accessible to the employees for a period of 30 calendar days. 


\section{Highlights of the NIOSH Health Hazard Evaluation}

\section{Evaluation of hypersensitivity pneumonitis among workers in machining areas}

NIOSH investigators conducted this evaluation at the request of management and the union to try to learn more about why some employees at the DaimlerChrysler Indiana Transmission Plant (ITP) became sick with hypersensitivity pneumonitis, a disease of the lungs.

\section{What NIOSH Did}

- We reviewed medical and industrial hygiene records.

- We tried to evaluate short term "peak" exposures to coolant mist of some workers entering enclosed machines.

- We handed out a questionnaire to employees in some departments to find out who was having symptoms.

- We drew blood from some employees to measure substances involved in the immune system.

\section{What NIOSH Found}

- Daily average air levels of coolant aerosol were below the NIOSH recommended level.

- Different types of bacteria and fungi were found in the coolant and in the parts-washers.

- Seven employees had hypersensitivity pneumonitis from June 2001 to January 2002.

- Our testing did not help us determine a single cause of the hypersensitivity pneumonitis.

- ITP has already taken steps to eliminate or reduce the exposures to coolant that might be causing the hypersensitivity pneumonitis.

\section{What ITP Managers Can Do}

- Do not allow workers to enter the enclosed machines while the coolant is running and until the ventilation has removed the coolant mist.

- Maintain a safety and health program related to metalworking fluids for employees working in the machining areas.

- Continue to communicate with employees and the union about health and safety issues.

\section{What ITP Employees Can Do}

- Do not enter the enclosed machines while the coolant is running, and until the ventilation has removed the coolant mist.

- Continue to attend all training sessions given by the union and management.

- Continue to follow instructions on use and maintenance of machines and coolant.

- Continue to report all health problems that might be related to work to the plant medical department.

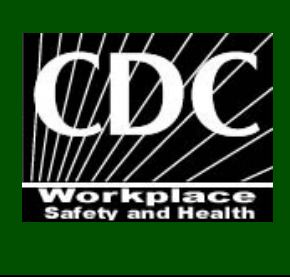

What To Do For More Information:

We encourage you to read the full report. If you

would like a copy, either ask your health and

safety representative to make you a copy or call

1-513-841-4252 and ask for

HETA Report \#2002-0155-2886

\section{Health Hazard Evaluation Report 20020155-2886}




\title{
DaimlerChrysler Indiana Transmission Plant Kokomo, Indiana December 2002
}

\author{
Douglas Trout, MD, MHS \\ Joshua Harney, MS
}

\section{SUMMARY}

In February and March 2002, the National Institute for Occupational Safety and Health (NIOSH) received requests from employees of the Indiana Transmission Plant (ITP) in Kokomo, Indiana, the International Union of United Automobile, Aerospace, and Agricultural Implement Workers of America (UAW), and DaimlerChrysler corporate management to conduct a health hazard evaluation (HHE). The request concerned respiratory problems and hypersensitivity pneumonitis (HP) thought to be associated with occupational exposures to metalworking fluids (MWFs) at ITP. The request specifically asked for assistance in assessing peak exposures to MWF aerosol and in laboratory testing to determine whether mycobacteria isolated from bulk samples of MWF at ITP might be the causative agent in the observed illnesses. In response to the HHE request, NIOSH investigators performed multiple site visits in April-July 2002.

The plant primarily uses metalworking machines which are enclosed and exhausted to the outdoors. Review of industrial hygiene information revealed that all but one of the company's recent measurements (including area samples [using a direct-reading instrument] and personal breathing zone samples) of MWF aerosol were below the current NIOSH recommended exposure limit for MWF aerosol (total particulate mass) of 0.5 milligrams per cubic meter $\left(\mathrm{mg} / \mathrm{m}^{3}\right)$. Fifty-five percent ( 28 of 51) of the direct-reading measurements were below $0.2 \mathrm{mg} / \mathrm{m}^{3}$. Analysis of bulk samples from the central MWF systems revealed contamination of several systems with Mycobacteria immunogenum. Several parts washers in machining departments were also contaminated with fungi of the genus Fusarium. Subsequent to several workers being diagnosed with HP, ITP took actions related to: 1) maintenance and monitoring of MWF;2) cleaning and re-charging of machines and central systems, and 3) modification of work practices related to entry into enclosed machines (including a new standard operating procedure requiring MWF to be shut off within machine enclosures during work tasks inside the enclosures).

Based on our review of industrial hygiene records, the engineering controls in place at ITP appeared to be effectively maintaining the workers' ambient exposure to MWF aerosol to concentrations substantially less than the NIOSH REL. The actions taken by ITP in response to workers' illnesses directly addressed the potential for workers to be exposed to greater concentrations of MWF aerosol for short periods of time due to job tasks which entail entering the machine tool enclosures. To evaluate the potential for such peak exposures to occur even after the change in operating procedures regarding MWF flow in the machines, the NIOSH industrial hygiene evaluation involved use of video exposure monitoring (VEM, a real-time aerosol monitor along with digital video). Unfortunately, technical difficulties in performing this sampling prohibited us from collecting any interpretable data. Had these data been interpretable, they are likely to have differed from the MWF aerosol concentrations to 
which workers may have been exposed prior to the institution of the new procedures (during the time the workers were diagnosed with HP). For that reason, a return site visit to perform the VEM at ITP was not conducted.

The medical evaluation included medical record review, questionnaire administration, and analysis of the blood of 56 workers for factors related to cell-mediated and humoral immunity. The goal of the questionnaire was to identify symptomatic and asymptomatic groups of employees to take part in an immunologic evaluation which would help us determine if workers were sensitive to M. immunogenum. Using three distinct assay systems, we evaluated the secretion of three different cytokines, including interferon gamma (IFN- $\gamma$ ), tumor necrosis factor alpha (TNF- $\alpha$ ), and interleukin 8 (IL-8).

A total of 19 medical records were reviewed for the HHE, and seven persons met the definition of HP. Among the seven were 2 operators, 2 job setters, 2 toolmakers, and one janitor. Among these seven workers, symptoms began between June 2001 and January 2002. After providing informed consent, 58 workers were scheduled for participation in our medical evaluation, including six of the seven workers with HP. An index measure of IL-8 was statistically significantly greater among those exposed to MWF compared to the unexposed. There were no statistically significant differences in the concentrations of IFN- $\gamma$ (both absolute secretion and index values) between the groups using these assays. Antibody levels against both M. immunogenum and Fusarium antigens were greater among persons with HP compared to those without HP. Antibody levels against $M$. immunogenum were greater among persons exposed to MWF compared to those unexposed. The results of our testing for antibodies against $M$. immunogenum were consistent with antibody testing (in other settings) against causative antigens in the evaluation of other types of HP. However, based on antibody testing alone, we cannot determine which antigen(s) are involved in the pathogenesis of HP observed among workers at ITP.

Seven employees working in the machining areas of ITP met our case definition for HP. A number of interventions were made by ITP in response to these illnesses. We cannot determine which intervention(s) were effective in reducing or eliminating the exposure(s) related to HP, however, the successful return of some affected workers to machining areas suggests that the causative exposure(s) have been substantially reduced in those areas. The engineering controls in place at ITP appeared to be effectively maintaining the workers' ambient exposure to MWF aerosol to concentrations substantially less than the NIOSH-recommended exposure limit. Our evaluation suggests that changes in work practices, implemented by ITP during the course of this HHE, would likely reduce short-term exposures to MWF aerosol and minimize potential health effects related to exposure to MWF. Recommendations are provided to assist in minimizing safety and health issues related to occupational exposures to MWF at ITP.

KEYWORDS: SIC 3714 (Motor vehicle parts and accessories): hypersensitivity pneumonitis, HP, metalworking fluids, MWF, machining, Mycobacterium immunogenum, Fusarium, cytokine, interferon, interleukin. 


\section{TABLE OF CONTENTS}

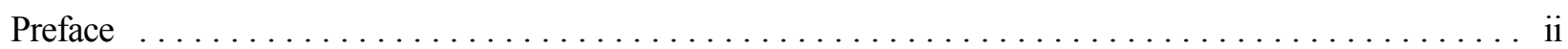

Acknowledgments and Availability of Report $\ldots \ldots \ldots \ldots \ldots \ldots \ldots \ldots \ldots \ldots \ldots \ldots \ldots \ldots \ldots \ldots \ldots$

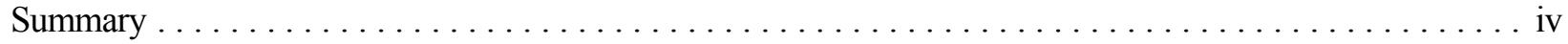

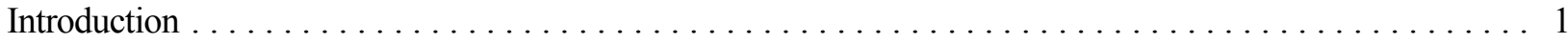

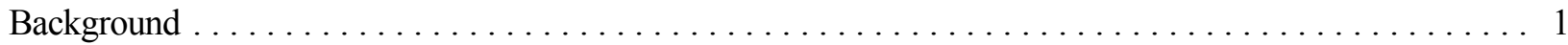

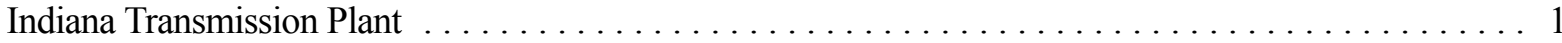

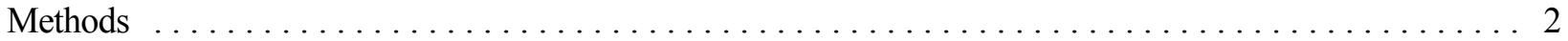

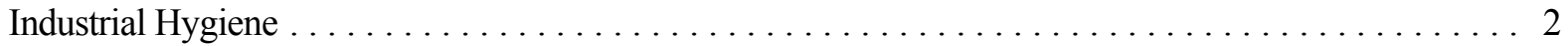

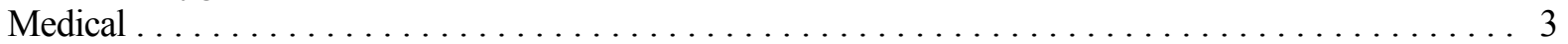

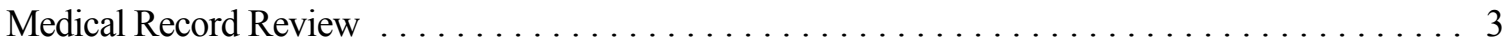

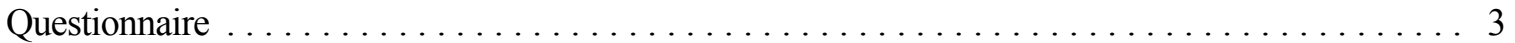

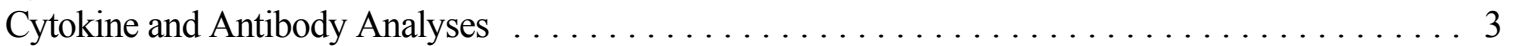

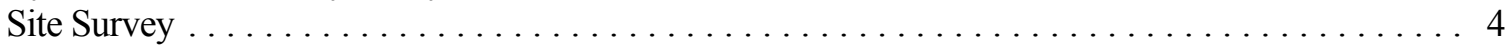

Evaluation Criteria $\ldots \ldots \ldots \ldots \ldots \ldots \ldots \ldots \ldots \ldots \ldots \ldots \ldots \ldots \ldots \ldots \ldots \ldots \ldots$

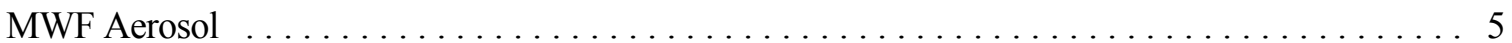

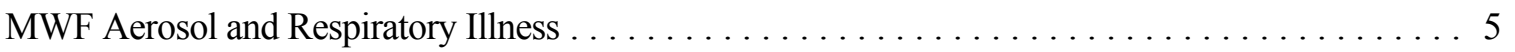

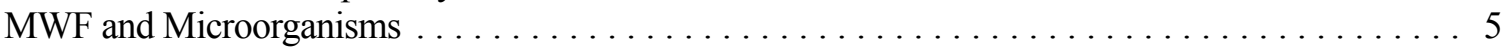

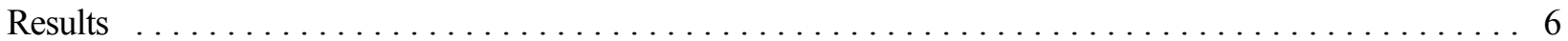

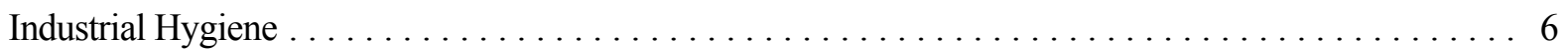

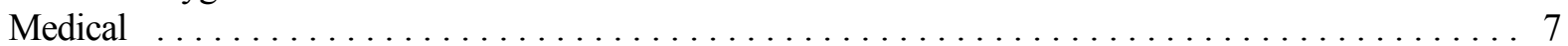

Medical Record Review $\ldots \ldots \ldots \ldots \ldots \ldots \ldots \ldots \ldots \ldots \ldots \ldots \ldots \ldots \ldots$

Questionnaire Administration and Selection of Participants for Laboratory Testing $\ldots \ldots \ldots \ldots 7$

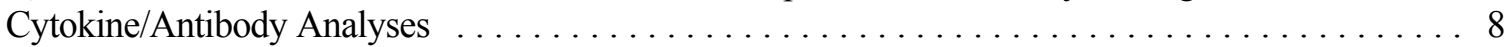

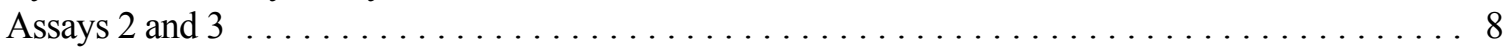

Comparisons Between Assays . . . . . . . . . . . . . . . . . . . . . . . . . . . . 9

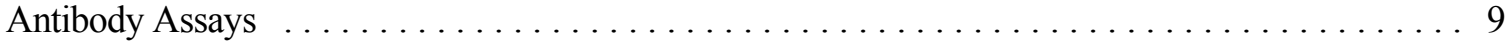

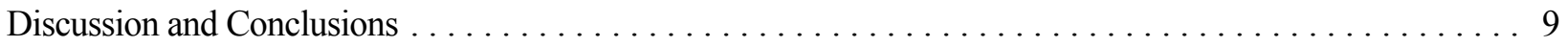

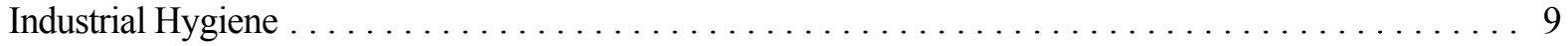

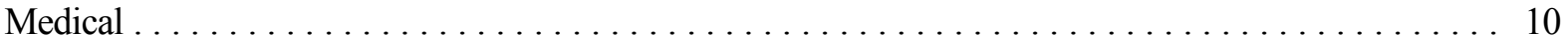

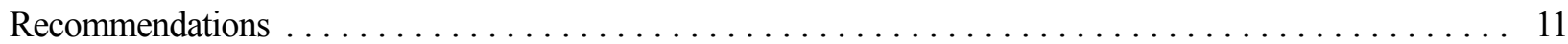

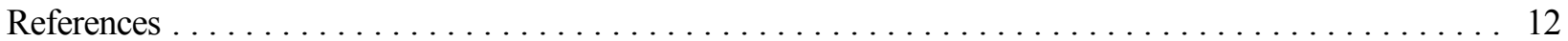




\section{INTRODUCTION}

In February and March 2002, the National Institute for Occupational Safety and Health (NIOSH) received requests from employees of the Indiana Transmission Plant (ITP) in Kokomo, Indiana, the International Union of United Automobile, Aerospace, and Agricultural Implement Workers of America (UAW), and DaimlerChrysler corporate management to conduct a health hazard evaluation (HHE). The request concerned respiratory problems and hypersensitivity pneumonitis (HP) thought to be associated with occupational exposures to metalworking fluids (MWFs) at ITP. The request specifically asked for assistance in two areas: 1) assessment (requesting use of video exposure monitoring [VEM] techniques) of peak exposures to MWF aerosol experienced by workers performing operations inside machine enclosures; and 2) laboratory testing to determine whether mycobacteria isolated from bulk samples of MWF was the causative agent in the observed illnesses.

In response to the HHE request, in April 2002, NIOSH investigators performed an initial site visit to meet with the requestors, perform a site walkthrough, and conduct initial record reviews. An industrial hygiene evaluation, consisting primarily of exposure assessment using VEM, was conducted in May 2002. In June 2002, a questionnaire was administered to employees in selected ITP departments, and in July 2002, a medical survey involving blood tests among selected employees was performed on-site. In November 2002, all study participants were informed in writing of the results of their individual medical tests.

Although this HHE primarily concerned HP related to occupational exposure to MWF, concerns related to potential occupational exposure to Legionella bacteria were also addressed. On April 29, 2002, a letter was sent to ITP and UAW representatives containing information and recommendations related to Legionella and legionellosis. The information reviewed, and discussed in that letter, provided no indication that ITP workers had been ill as a result of exposure to Legionella (from occupational or nonoccupational sources). Information concerning Legionella will not be discussed in this report.

\section{BACKGROUND}

\section{Indiana Transmission Plant}

Approximately 2000 production workers are employed at ITP, which manufactures automatic transmissions and transmission components in a 1.5 million square foot facility that is approximately three years old. There are more than 30 central MWF systems in use, including approximately 14 with central reservoirs ranging in size from 8,000 to 12,000 gallons, supplying fluids to machines in the departments of concern. Many types of machining take place at ITP (including grinding, cutting, polishing, and broaching) on parts which are primarily steel and aluminum. The plant primarily uses machines which are enclosed and exhausted to the outdoors. ITP has a medical department which includes on-site medical and nursing staff. At the time of the HHE request, 16 workers, working in or around the departments of concern, had reported to the medical department with respiratory symptoms that were evaluated by the medical department for potential work-relatedness. Among those workers were several with HP.

During the opening conference, information concerning work practices and industrial hygiene exposure monitoring was reviewed. Parts to be machined are typically added and removed from machines via automated processes, and machine operators, in contrast to tool makers and job setters, do not normally open the machines' enclosures. Union and management representatives reported that prior to early 2002, MWF flow was not routinely halted in the machines during tool making and job setting activities. Review of industrial hygiene information revealed that all but one of the recent measurements (using a direct-reading instrument) of MWF aerosol were below the current NIOSH recommended exposure limit (REL) for MWF 
aerosol (total particulate mass) of 0.5 milligrams per cubic meter $\left(\mathrm{mg} / \mathrm{m}^{3}\right)$, and that $55 \%$ (28 of 51) of samples were below $0.2 \mathrm{mg} / \mathrm{m}^{3}$. Personal breathing zone (PBZ) sample results from surveys done by a contractor in January and February, 2002, were consistent with these real-time monitoring results; 17 of 18 PBZ air samples among employees in machining areas were below the NIOSH REL. Bulk sampling of central MWF systems in Departments 5200,5400 , and 5500, performed by ITP, revealed contamination of several systems with Mycobacteria immunogenum. Several parts washers in machining departments were also found to be contaminated with fungi of the genus Fusarium.

Subsequent to several workers being diagnosed with HP, a number of actions were taken by ITP. The primary actions taken included: 1) standard operating procedure (SOP) governing the flow of MWF to the machine had been changed so that MWF was not flowing through the machine's enclosure during tool making and job setting tasks; 2) mist collector filter maintenance was reviewed; 3) other MWF maintenance and monitoring procedures were modified, and the "pellet" stain (a semi-quantitative test used to monitor alive and dead Mycobacteria in the MWF) had been incorporated into the procedures; and 4) a detailed draining, cleaning, and re-charging protocol was instituted for all machines (including machine tools and parts washers) and systems in areas where affected employees worked and in neighboring areas or areas utilizing similar processes. It was recognized by ITP's health and safety staff that persons diagnosed with HP were working in areas using a specific semi-synthetic MWF with a triazine-based biocide incorporated in the formulation. During the re-charging process, several MWFs were used to replace this MWF in various areas of the plant; currently a primary MWF in use at the plant is a semisynthetic MWF which includes an isothiazolinone-based biocide.

\section{METHODS}

\section{Industrial Hygiene}

The primary goal of the NIOSH industrial hygiene evaluation involved an assessment, using VEM, of peak exposures to which some employees may be exposed during routine operations at ITP. A realtime aerosol monitor (HazDust III model HD-1002 [Environmental Devices Corp., Haverhill, MA.]) with a thoracic preclassifier was used to collect personal breathing zone (PBZ) samples during normal working operations. A digital video camera was used to film the work as the HazDust collected exposure data. By synchronizing the clock on the video camera with the HazDust, we hoped to create a video overlay to show the exposure-task relationship.

The HazDust uses the light scattering properties of particulate passing through the instrument's internal laser beam to give the user airborne particulate concentration information. Because this information is dependent on the optical properties of the particulate being sampled, which may be different from the particulate used by the HazDust manufacturers to calibrate the instrument initially, a field calibration method was needed. A tared, 37mm polytetrafluoroethylene (PTFE) filter was placed downstream of the HazDust sensor chamber, and air was drawn from the worker's breathing zone, through this sensor chamber, and through the filter at a rate of 2 liters per minute. In this way, all the material that the HazDust detected was collected on the filter, which was to be analyzed according to NIOSH Draft Method 5524. ${ }^{1}$ The result from the gravimetric filter analysis is used to adjust the HazDust field data so that results reflect true airborne concentrations.

\section{Medical}

\section{Medical Record Review}


The NIOSH medical officer reviewed medical records available from the ITP medical department concerning employees from machining areas of the plant who had presented with respiratory symptoms and/or illnesses potentially related to their work. Included among these were records gathered by ITP from outside physicians.

\section{Questionnaire}

For the purposes of this HHE, the NIOSH medical officer developed a brief questionnaire which included questions concerning job duties, current symptoms, and medical history. The goal of the questionnaire was to identify groups of employees to take part in the blood testing described below. In June 2002, the questionnaire was distributed to employees in departments 5200, 5400, 5500, and 6000. Department 6000 is an assembly department which is located next to the machining departments of concern, but which does not use MWF in usual operations. The questionnaires included information about the HHE and the planned laboratory testing, and also included a section in which participants could indicate whether they would consider taking part in the planned blood testing. The completed questionnaires were returned to the NIOSH medical officer for analysis.

Data from the questionnaires were used to select potential participants in the survey. Based on laboratory capabilities, we planned to recruit approximately 15 participants from each of the following four groups: Group 1: employees working in machining areas ("exposed" to MWF) who were suspected or confirmed to have respiratory illness (possibly including HP) by their physicians (this is the group of workers identified by the ITP Medical Department); Group 2: employees from the machining areas who were symptomatic but who had not presented to the facility medical department; Group 3: employees from the machining areas who were asymptomatic; and Group 4: employees from the assembly area ("unexposed" to MWF) who were asymptomatic. "Symptomatic" employees included those employees who reported on the questionnaire in the preceding year: a) chest flu (fever, shivering, cough, tired, weak, ache all over) or pneumonia, with symptoms related to work; and/or b) episode of breathing difficulty (such as wheezing, shortness of breath, and/or cough) with symptoms related to work. "Asymptomatic" employees were defined as employees who reported neither a) or b) above. HP was defined following the case definition used in the evaluation of respiratory illness among workers in a large machining plant in 1995-1996 (Table 1); ${ }^{2}$ we considered all persons with 'possible,' 'probable,' or 'definite' HP to meet our case definition for HP. If more than 15 potential participants were available from any of the groups, 15 participants were to be chosen randomly from the total number.

\section{Cytokine and Antibody Analyses}

To evaluate whether M. immunogenum, which previously was cultured from the MWF at ITP, may be related to the HP diagnosed among some workers at the plant, we performed blood testing on the employees in the groups mentioned above to measure cytokine and antibody responses. Our cytokine analyses measured the response of workers' peripheral blood mononuclear cells (PBMCs) after the cells were exposed to a $M$. immunogenum antigen preparation in the laboratory. A finding of increased cytokine secretion from PBMCs of workers with HP compared to that from workers without HP would provide some evidence that the affected workers were specifically sensitized to $M$. immunogenum. Further discussion of the laboratory analyses is in Appendix 1.

Antibody testing was performed by NIOSH Health Effects Laboratory Division (HELD) Analytical Services Branch to assess the presence of immunoglobulin $\mathrm{G}(\mathrm{IgG})$ against $M$. immunogenum and Fusarium (see Appendix 1 for methods) which had been found to be contaminants in the MWF and parts washers (respectively) at ITP. Antibodies to $M$. immunogenum were measured against two antigen preparations of $M$. immunogenum. 
Comparisons of the cytokine concentrations (Assays 1 and 2), ELISPOT results (Assay 3), and antibody levels were made by case (HP case versus non-case) and exposure (exposed versus unexposed) status using the Wilcoxon Two-sample test (a nonparametric test). A p value of $\leq .05$ was used to indicate statistical significance. Because the data were non-normally distributed, the median was used as the measure of central tendency. If the individual cytokines were related to development of HP, we would expect to find increased secretion of the cytokines among persons who have HP compared to those who do not have HP.

\section{Site Survey}

On July 10, 2002, the NIOSH medical officer met with ITP employees identified as potential study participants in Groups 1- 4 (described above). The purpose of this site visit was to explain the survey to individual employees and answer questions. Employees wishing to participate in the HHE provided informed consent. On July 15 and 31, 2002, NIOSH representatives returned to ITP to draw blood from the participants. Blood samples were stored on ice and were sent immediately to laboratories at NIOSH and the University of Michigan Medical Center. In the laboratories, the blood was prepared, and analyses conducted, as indicated for each type of assay. The protocol for this HHE was approved by the NIOSH and University of Michigan human subjects review boards.

\section{EVALUATION CRITERIA}

As a guide to the evaluation of the hazards posed by workplace exposures, NIOSH field staff employ environmental evaluation criteria for the assessment of a number of chemical and physical agents. These criteria are intended to suggest levels of exposure to which most workers may be exposed up to 10 hours per day, 40 hours per week for a working lifetime without experiencing adverse health effects. It is, however, important to note that not all workers will be protected from adverse health effects even though their exposures are maintained below these levels. A small percentage may experience adverse health effects because of individual susceptibility, a preexisting medical condition, and/or a hypersensitivity (allergy). In addition, some hazardous substances may act in combination with other workplace exposures, the general environment, or with medications or personal habits of the worker to produce health effects even if the occupational exposures are controlled at the level set by the criterion. These combined effects are often not considered in the evaluation criteria. Also, some substances are absorbed by direct contact with the skin and mucous membranes, and thus potentially increases the overall exposure. Finally, evaluation criteria may change over the years as new information on the toxic effects of an agent become available.

The primary sources of environmental evaluation criteria for the workplace are: (1) NIOSH Recommended Exposure Limits (RELs), ${ }^{3}$ (2) the American Conference of Governmental Industrial Hygienists' (ACGIH®) Threshold Limit Values (TLVs $\left.{ }^{\circledR}\right),{ }^{4}$ and (3) the U.S. Department of Labor, Occupational Safety and Health Administration (OSHA) Permissible Exposure Limits (PELs). ${ }^{5}$ Employers are encouraged to follow the OSHA limits, the NIOSH RELs, the ACGIH TLVs, or whichever are the more protective criteria.

OSHA requires an employer to furnish employees a place of employment that is free from recognized hazards that are causing or are likely to cause death or serious physical harm [Occupational Safety and Health Act of 1970, Public Law 91-596, sec. 5.(a)(1)]. Thus, employers should understand that not all hazardous chemicals have specific OSHA exposure limits such as PELs and short-term exposure limits (STELs). An employer is still required by OSHA to protect their employees from hazards, even in the absence of a specific OSHA PEL.

A time-weighted average (TWA) exposure refers to the average airborne concentration of a substance during a normal 8- to 10-hour workday. Some 
substances have recommended STEL or ceiling values which are intended to supplement the TWA where there are recognized toxic effects from higher exposures over the short-term.

\section{MWF Aerosol}

NIOSH recommends that occupational exposures to MWF aerosols be limited to $0.4 \mathrm{mg} / \mathrm{m}^{3}$ of thoracic particulate mass as a TWA concentration for up to 10 hours (hrs)/day during a 40-hr work week, measured according to NIOSH Method $0500 .{ }^{6}$ The $0.4 \mathrm{mg} / \mathrm{m}^{3}$ concentration thoracic particulate mass corresponds to approximately $0.5 \mathrm{mg} / \mathrm{m}^{3}$ total particulate mass.

This REL is intended to reduce the respiratory disorders associated with MWF exposures in the workplace. However, concentrations of MWF aerosols should be kept below the REL where possible because some workers have developed work-related asthma, hypersensitivity pneumonitis (HP), or other adverse respiratory effects when exposed to MWFs at lower concentrations. Limiting exposure to MWF aerosols is also prudent because certain MWF exposures have been associated with various cancers. In addition, limiting dermal (skin) exposures is critical to preventing allergic and irritant skin disorders related to MWF exposure. In most metalworking operations, it is technologically feasible to limit MWF aerosol exposures to 0.4 $\mathrm{mg} / \mathrm{m}^{3}$ or less.

\section{MWF Aerosol and Respiratory IIIness}

Studies summarized in the NIOSH Criteria Document provide evidence that occupational exposure to MWF aerosols causes symptoms consistent with airways irritation, chronic bronchitis, asthma, and hypersensitivity pneumonitis. In many cases, the specific agent(s) responsible for these effects is (are) not known. HP (also called extrinsic allergic alveolitis) is a spectrum of granulomatous, interstitial lung diseases which occur after repeated inhalation and sensitization to a wide variety of microbial agents (bacteria, fungi, amoebae), animal proteins, and low-molecular weight chemical antigens. For example, fungi of the genus Fusarium have been implicated as a cause of HP in a home environment. ${ }^{7}$ The time of onset of HP after initial exposure to an antigen may range from a period of weeks to years. It is marked by a pneumonitis, which is reversible if exposure to the antigen is stopped; continued exposure can lead to a chronic interstitial fibrosis or scarring of the lungs. HP associated with exposure to MWFs has been described in several reports. $^{8,9,10}$

In general, HP is marked by nonspecific symptoms. Acute HP begins in the first 12 hours after exposure with cough, dyspnea (shortness of breath), chest tightness, fevers, chills, malaise, and myalgias (muscle aches). The symptoms of the subacute and chronic forms of HP include cough, dyspnea, wheezing, loss of appetite, and weight loss. The diagnosis should be considered in anyone with recurrent "pneumonia" or recurrent or persistent unexplained respiratory symptoms; suggestions for uniform criteria for the diagnosis of HP have been published. ${ }^{11}$ The authors of a publication concerning an outbreak of respiratory illness among workers in a large machining plant in 1995-1996 used an epidemiologic case definition for HP based on seven criteria. $^{2}$ A 'possible' case of HP was defined as a person meeting 4 criteria, a 'probable' case met 5 criteria, and a definite case met 6 or 7 criteria.

\section{MWF and Microorganisms}

Historically, microbial contamination of MWF has been a problem primarily because of the microbial growth effects on fluid quality and performance. Fluid degredation from microorganisms may result in changes in fluid viscosity, and the acid products of fermentation may lower the $\mathrm{pH}$ of the fluids, causing corrosion of machined parts. Anaerobic bacteria, specifically the sulfate reducers, may produce hydrogen sulfide and other toxic gases. Excessive microbial growth may result in clogged filters and ports and may interfere with the machining operations. 
Water-based MWFs are excellent nutritional sources for many kinds of bacteria and fungi. The predominant species routinely recovered from MWFs are virtually identical to those routinely recovered from natural water systems. Many species that grow in MWFs secrete waste products that serve as a nutritional substrate for organisms with more restrictive nutritional needs. Well-maintained MWFs should have bacterial concen-trations below $10^{6}$ colony forming units per $\mathrm{mL}(\mathrm{CFU} / \mathrm{mL})$ of fluid. ${ }^{12}$

Some individuals manifest increased immunologic responses to microorganisms, or their metabolites, in the environment. Although microbial contamination of MWFs poses an occupational hazard, there are insufficient data to determine acceptable levels of microbial contamination in the air. In addition, allergic or hypersensitivity reactions can occur even with relatively low air concentrations of allergens, and individuals differ with respect to immunologic susceptibilities. Although some pathogenic organisms have been identified in oil emulsion MWFs in the past, ${ }^{13,14}$ most pathogens do not persist well in most MWFs. ${ }^{15,16,17,18}$

M. immunogenum has been found as a contaminant in other machining plants where there have been outbreaks of HP. Previous work has shown that standard serologic tests for the presence of antibody can demonstrate that employees are exposed to an antigen (such as $M$. immunogenum), but antibody status does not necessarily provide information regarding the cause of HP among those workers who are exposed. $^{19,20}$ The most direct approach to documenting a causal link between specific constituents/contaminants of MWF and acute HP would be to perform specific inhalation challenge with suspected constituents/contaminants. ${ }^{21}$ In that type of test, symptoms and pulmonary function are observed after controlled exposure to a suspected antigen. That test is problematic in field studies, however, because it involves a potential for significant morbidity for the participant. Because HP is thought to involve a cell-mediated immune response, researchers have measured T-lymphocyte function as a surrogate for clinical illness. ${ }^{21}$ One study found that peripheral blood cells from subjects with pigeon breeder's disease (a form of HP) produced increased amounts of a cytokine compared with those from asymptomatic persons. ${ }^{22} \mathrm{IL}-8$, TNF$\alpha$, and IFN- $\gamma$ have been suggested as playing a role in the pathogenesis of other types HP, but have not been studied in the context of MWF exposure. ${ }^{23}$

\section{RESULTS}

\section{Industrial Hygiene}

During the beginning of this evaluation, but prior to conducting VEM, the plant implemented a standard operating procedure that altered the exposure scenario for job setting and toolmaking tasks. In the period of time during which workers developed HP, job-setters and toolmakers were able to perform their work tasks within a machine enclosure while MWF was flowing within that enclosure. The new SOP required MWF to be shut off within the machine enclosure during these tasks. This would be expected to decrease the exposure of these employees to MWF aerosol.

Despite this change in procedures for work in the machining areas, seven separate tasks were monitored using VEM to see if peak exposures to MWF aerosol could be documented for specific tasks. Tasks to be monitored were chosen based on the work orders available for review at the beginning of the shift, with priority given to jobs in departments in which HP had occurred among employees, and secondarily to those tasks expected to produce 'high' exposures based on observation of work practices. Unfortunately, technical difficulties in performing this sampling prohibited us from collecting any interpretable data. Because of the new procedures affecting MWF flow within the enclosures, had these data been interpretable, they are likely

to have differed from the MWF aerosol concentrations to which workers may have been exposed during the time the workers were diagnosed with HP. For that reason, a return site visit to perform VEM at ITP was not conducted. 


\section{Medical}

\section{Medical Record Review}

At the start of the HHE, 16 medical records were available for review, and determination of participants in Group 1 was based on that review. Three additional medical records subsequently became available and were also reviewed. Eighteen of the 19 persons were from 5 different departments; one medical record was reviewed for a worker whose department was not known (that record was very brief). Job titles included operator (8 persons), job setter (4 persons), toolmaker ( 2 persons), machine repair, janitor, and pipefitter (one each), and unknown (two persons). Using the case definition in Table 1, 7 persons met a definition for possible (2), probable (2), or definite (3) HP. In several instances the records were incomplete, so that not meeting a criterion in any given instance may have been related to a specific test not being performed, or related to test results not being included in the medical record. Among the seven meeting the case definition for HP were 2 operators, 2 job setters, 2 toolmakers, and one janitor. Among the remaining 12 workers, eight were determined by record review to have workrelated respiratory or upper respiratory symptoms (work-relatedness was determined by history and/or decision of treating doctor to use work restrictions). Four of the 12 workers reported respiratory symptoms with minimal evidence for workrelatedness in the medical record and were determined for the purpose of this record review to have respiratory symptoms that were not workrelated.

Among those workers meeting the case definition for HP, symptoms began between June 2001 and January 2002. One of these workers was away from work during the period of this HHE for reasons reported to be unrelated to the HP; all six of the others had continued to work at ITP. Several of these six workers have returned to their original jobs at ITP. All workers received ongoing follow-up at the ITP medical department and with personal physicians.

Among the 15 workers with work-related respiratory conditions mentioned above ( 7 with HP and 8 with other work-related respiratory conditions), 11 (73\%) participated in our laboratory testing, including 6 of the 7 with HP and 5 of the 8 categorized as having other respiratory disorders.

\section{Questionnaire Administration and Selection of Participants for Laboratory Testing}

Workers eligible for participation in the laboratory portion of the HHE in Group 1 (groups defined in Methods) included all those persons from machining departments with documented or suspected HP, based on medical record review. At the time the groups were being organized, 16 persons had been evaluated in the ITP Medical Department for possible work-related respiratory disorders. Of those, two were initially determined by the NIOSH medical officer not to have work-related respiratory symptoms and were removed from the group, and so the remaining 14 workers made up the possible Group 1 participants.

The goal of the questionnaire survey was to identify potential participants in Groups 2- 4. Although not used for group categorization, questionnaires were also completed by all participants in Group 1 . Of the 150 questionnaires distributed to workers in the departments of interest, 140 (93\%) were completed and returned. Of the 140 persons who participated in the questionnaire, $36(26 \%)$ declined to participate any further in the HHE. Among the remaining 104, 22 workers from the machining areas reported workrelated symptoms (and therefore eligible for Group 2 ), and 13 were asymptomatic (and therefore eligible for Group 3). Fourteen of the 104 were asymptomatic workers from the assembly area (Department 6000) (and therefore eligible for Group 4). Initially, 15 of the 22 symptomatic workers from the machining areas were randomly selected to be offered the laboratory testing as part of Group 2. 
Therefore 56 workers were initially identified as potential participants for the laboratory portion of the survey for Groups 1-4.

The 56 eligible workers were asked to participate in an information session on July 10, 2002, in which the NIOSH medical officer explained the survey and obtained informed consent. Seven of the workers on the original list of 56 were not available for the July 10 and July 15 (testing) dates. During that time, nine employees who worked in the departments of concern, but who had not been at work during the original questionnaire administration, were recruited. All nine completed the questionnaire, were grouped according to their exposure status and symptoms as reported in the questionnaire, and participated in the laboratory testing. Therefore, 58 workers were scheduled for the blood draw on July 15,2002 . On July 15,51 blood samples were drawn; 7 of the 58 were away from work that day. Due to timing of shipment of blood samples, five of the 51 blood samples could not be transported to the University of Michigan laboratory. Three of the seven workers unavailable on July 15 provided blood samples when NIOSH representatives returned to ITP on July 31, 2002; those samples were analyzed only by the NIOSH laboratory because the samples could not be transported to the University of Michigan laboratory. This yielded the following: 46 samples analyzed by the Michigan laboratory and 54 samples analyzed by the NIOSH laboratory.

\section{Cytokine/Antibody Analyses}

Cytokine and antibody results are presented by illness (HP) and exposure status; demographic summaries of those groups are presented in Tables 2 and 3.

Assay 1 The limit of detection(LOD) for each of the three cytokines after stimulation with $M$. imunogenum, M. tuberculosis, and RPMI was 60 picograms per milliliter $(\mathrm{pg} / \mathrm{mL})$; the LOD for the cytokines after stimulation with lipopolysaccharide
(LPS) was $300 \mathrm{mg} / \mathrm{mL}$. IFN- $\gamma$ was detected above the LOD (63 and $77 \mathrm{pg} / \mathrm{mL}$ ) in only two of 46 samples after stimulation with $M$. immunogenum one sample from a worker with HP, one from a worker in Group 4 (unexposed, asymptomatic). TNF- $\alpha$ was detected above the LOD (89 and 93 $\mathrm{pg} / \mathrm{mL}$ ) in only two samples after stimulation with $M$. immunogenum - one sample from a worker with HP, and one from a worker in Group 1 with a respiratory illness other than HP.

Summary data for IL-8 secretion are presented in Tables 4 (HP cases versus non-cases) and 5 (MWFexposed versus those unexposed to MWF). There were no statistically significant differences in the concentrations of IL-8 among the persons with HP compared to those without HP, or among the persons exposed to MWF compared to those unexposed; the median values were greater among the persons without HP and among the persons unexposed to MWF. There was no statistically significant difference in the index measure for IL-8 secretion (IL-8 \%LPS) between persons with HP and without. IL-8 was statistically significantly greater among those exposed to MWF (median 0.33) compared to the unexposed (median 0). Complete data from Assays 1 (IL-8), 2, and 3 are presented in Appendix 2.

\section{Assays 2 and 3}

Summary data for IFN- $\gamma$ secretion are also presented in Tables 4 and 5. There were no statistically significant differences in the concentrations of IFN- $\gamma$ (both absolute secretion and index value [IFN- $\gamma$ $\%$ PHA]) as determined by Assay 2 among the persons with HP compared to those without HP, or among the persons exposed to MWF compared to those unexposed. The median values for both measures were greater among the persons with HP and among the persons exposed to MWF.

There were no statistically significant differences in the absolute and index values for IFN- $\gamma$ secretion as determined by Assay 3 among the persons with HP compared to those without HP and among exposed 
persons compared to those unexposed to MWF. The median values for both absolute and index measures were higher among HP cases compared to non-cases, as was the median value for the index level among exposed persons compared to those unexposed to MWF. The median values for the absolute measure was lower among exposed persons compared to those unexposed.

\section{Comparisons Between Assays}

IFN- $\gamma$ secretion as determined by Assay 2 did not correlate with that determined by Assay $3(\mathrm{r}=0.2$ between the indexes reported in Tables 4 and 5). IFN- $\gamma$ secretion from Assay 1 could not be compared with that from the other assays because of the low concentrations produced. The IFN- $\gamma$ secretion from Assay 2 did not correlate with IL-8 secretion from Assay $1(\mathrm{r}=0.06)$.

\section{Antibody Assays}

Antibody levels against both $M$. immunogenum antigens and the Fusarium antigen were greater among persons with HP compared to those without HP (Table 4). Antibody levels against $M$. immunogenum were greater among persons exposed to MWF compared to those unexposed (Table 5). Because antibody production to inhaled antigens has been shown to be inhibited by cigarette smoking, ${ }^{23}$ the potential confounding effect of current cigarette smoking was assessed by repeating the statistical analysis and excluding current cigarette smokers; this revealed no substantial change in the results.

\section{DisCUSSION AND CONCLUSIONS}

\section{Industrial Hygiene}

Based on the review of ITP's industrial hygiene records available for this HHE, the engineering controls in place at ITP appear to be effectively maintaining the workers' ambient exposure to MWF aerosol to concentrations substantially less than the NIOSH REL. However, descriptions of work practices and our observations, raised the concern that some workers at ITP may be exposed to greater concentrations of MWF aerosol for short periods of time due to job tasks which entail entering the machine tool enclosures. Our industrial hygiene sampling for this HHE was focused on trying to learn more about such potential exposures but technical problems prevented us from gathering interpretable data. Our review of records revealed that four of the seven persons meeting the case definition for HP were job setters or tool makers, workers whose jobs involve entering the machine tool enclosures. Based on this knowledge, and current limited information related to the importance of short-term "peak" exposures to MWF aerosol relative to average exposures, reduction in such "peak" exposures may be warranted. Primary methods to accomplish this reduction involve changes in engineering controls and work practices. Around the time the HHE was initiated, ITP changed SOPs for tool maintenance so that MWF flow is stopped or decreased when workers enter the enclosed machines. It is likely that this will decrease workers' short-term exposures to MWF aerosol. Such changes are consistent with the comprehensive safety and health plan recommended by NIOSH to minimize health effects related to occupational exposure to MWF. ${ }^{6}$

\section{Medical}

The primary goal of this evaluation was to learn more about $M$. immunogenum, which had been identified as a MWF contaminant in the areas of the facility where workers had been diagnosed with HP, and it's role in the etiology of HP among these workers. To accomplish our goal, we attempted to detect differences in levels of specific cytokines (whole blood and PBMC stimulation assays) between workers with HP and those without HP; we also evaluated cytokine levels between groups of workers exposed and unexposed to MWF. Except for the IL-8 \% LPS assay, our cytokine studies revealed no statistically significant relationships 
between secretion of the cytokines tested and either the presence of HP or exposure to MWF. Of the cytokine assays used in this HHE, Assay 2 for IFN- $\gamma$ consistently showed increased secretion among persons with HP compared to those without, although the differences were not statistically significant. A study of Assay 2 with a larger number of affected workers would be needed to make more definitive conclusions. However, HP is an illness with relatively low incidence, making it difficult to do such a study.

We also performed antibody studies on the serum of participating workers. The results of our testing for antibodies against $M$. immunogenum were consistent with antibody testing (in other settings) against causative antigens in the evaluation of other types of HP. For example, elevated levels of antibody against purified avian antigens have been associated with increased incidence of pigeon breeders disease (a form of HP), ${ }^{24}$ and increasing exposure to pigeons has been associated with increase in antibody response to pigeon antigens. ${ }^{25}$ We also found increased level of antibody against Fusarium (isolated from parts washers at ITP) among persons with HP (but not among persons exposed to MWF). As with other antibody testing, our antibody testing was non-specific in that we found elevated levels of M. immunogenum and Fusarium antibody in some persons without HP. MWF, as they are used in production facilities, are complex mixtures of multiple potential antigens, both microbial and chemical, and therefore, based on antibody testing alone, we cannot determine which antigen(s) are involved in the pathogenesis of HP observed among workers at ITP.

There were several limitations to our evaluation. Although we based our grouping of workers on the most up-to-date clinical information that was available to us, our records may have been incomplete, so it is possible that participants may have been misclassified in terms of case/non-case status. Likewise, it is possible that our departmentallevel determination of exposure status may have led to some misclassification of participants by exposure. This is particularly true concerning potential worker exposure to Fusarium, because our determination of MWF-exposure was based on the use of MWF in certain departments and not on the presence of parts washers (the machinery from which the Fusarium was isolated). Such misclassification may have made it appear as if no relationship exists between a test result and case or exposure status when such a relationship actually does exist. Finally, the fact that we were using PBMCs may be an important limitation of our laboratory work. Because the target organ of inhaled antigens thought responsible for HP is the lung, recent work related to the pathogenesis of HP has involved the cellular immune response of cells from the lung (obtained via bronchoalveolar lavage [BAL]). ${ }^{26}$ Cells obtained from BAL may be more accurate indicators of cellmediated immune responses occurring in the lung, however, these types of cells are not readily available from workers involved in field evaluations.

According to information reviewed for this HHE, all ITP workers diagnosed with HP initially returned to work to non-machining areas of the plant, and some of the affected workers have returned to their original work duties in machining areas. We are not aware of any ITP workers being diagnosed with HP after January 2002. A number of interventions were made by ITP in response to the illnesses among employees. The primary interventions involved improvements in maintenance, cleaning, and formulation of the MWF in the machining areas, as well as changes in controls and work practices related to worker entry in enclosed machines. We cannot determine which intervention(s) were effective in eliminating or reducing the exposure(s) related to HP, however, the successful return of some affected workers to machining areas suggests that the causative exposure(s) have been substantially reduced in those areas.

\section{RECOMMENDATIONS}

NIOSH recommends a comprehensive safety and health plan to minimize health effects related to occupational exposure to MWF - these recommendations are outlined in the NIOSHCriteria 
Document. ${ }^{6}$ Another source of useful recommendations regarding a systems approach to MWF maintenance and safety and health issues can be found on the internet site of Organization $\mathrm{R}$ e $\mathrm{s}$ o u r c e C o u n e lors : http://www.aware-services.com/orc/. The components of a comprehensive safety and health plan for MWF are in place at ITP; however, all such plans at any worksite require continued review to confirm that the elements of the plan are practiced regularly at the plant level. The following recommendations are provided to assist in continuing attempts to minimize safety and health issues related to occupational exposures to MWF at ITP.

1. Entrance of workers into machine tool enclosures with potentially elevated concentrations of MWF aerosol should be minimized. When such work activities are unavoidable, they should not occur until the ventilation of the tool has been able to reduce the concentration of MWF aerosol to ambient levels. If symptoms or illnesses recur among workers performing these types of work duties, further evaluation of MWF aerosol concentrations inside the enclosures, and consideration of further engineering and/or administrative controls for these work tasks, is warranted.

a) Workers exposed to MWF at concentrations above the REL should have respiratory protection. An air-purifying respirator equipped with an R- or Pseries filter would be appropriate. Because respiratory protection is usually the least desirable method of reducing exposures, the use of respiratory protection should not be considered a permanent solution. Respirators should only be used within the constraints of a comprehensive respiratory protection program. $^{27}$ Users must be trained, fit-tested, and medically cleared for their assigned respirator.

2. ITP should continue to monitor reported health problems in a systematic manner designed to identify particular job duties, work materials (such as particular MWFs), machines, or areas of the plant which may be associated with particular health effects.

a) Workers with respiratory and/or systemic symptoms must continue to be promptly evaluated by health professionals experienced with occupational and respiratory health issues. Individuals with definite or possible occupational respiratory diseases should be protected from exposures to presumed causes or exacerbators of the disease.

b) Physicians caring for individual employees who have experienced work-related health problems should make the final decisions concerning the timing and the nature of individual employees' ability to return to work. A gradual, step-wise approach to return to work should be considered. For example, employees who have been diagnosed with HP or similar illness, when judged able to return to work by their healthcare provider, may benefit from an initial trial of work in areas of the plant physically removed from machining processes (such as assembly areas). Subsequent issues, including return to work in the machining areas, as well as issues concerning potential use of respiratory protection, must then be handled on a case-by-case basis. Close clinical follow-up is required for all employees returning to work after having been restricted due to work-related illness. Employees who have developed HP or similar illness related to a substance(s) in the MWF may become symptomatic upon return to specific areas of the facility even after cleaning of the machines and the MWF systems and improvement of ventilation and engineering controls (even if MWF aerosol concentrations are less than the NIOSH REL).

c) In some cases, reassignment to areas where exposure is minimized or nonexistent may be medically advisable. In such cases, the reassigned worker should retain wages, seniority, and other benefits that might otherwise be lost by such a job transfer.

3. ITP and the UAW should continue to educate all ITP workers concerning occupational health concerns at ITP, and should continue to encourage employees to report health symptoms possibly related to workplace exposures to appropriate health professionals as soon as they occur. 


\section{REFERENCES}

1. NIOSH [1994]. Metalworking fluids (all categories) (DRAFT Method 5524). In: Eller PM, Cassinelli ME, eds. NIOSH manual of analytical methods. $4^{\text {th }}$ ed. Cincinnati, OH: U.S. Department of Health and Human Services, Public Health Service, Centers for Disease Control and Prevention, National Institute for Occupational Safety and Health.

2. Fox, J, et al. [1999]. Metal working fluidassociated hypersensitivity pneumonitis: an outbreak investigation and case-control study. AJIM 35:58-67.

3. NIOSH [1992]. Recommendations for occupational safety and health: compendium of policy documents and statements. Cincinnati, $\mathrm{OH}$ : U.S. Department of Health and Human Services, Public Health Service, Centers for Disease Control and Prevention, National Institute for Occupational Safety and Health, DHHS (NIOSH) Publication No. 92-100.

4. ACGIH [2002]. 2002 TLVs ${ }^{\circledR}$ and BEIs ${ }^{\circledR}$ : threshold limit values for chemical substances and physical agents. Cincinnati, OH: American Conference of Governmental Industrial Hygienists.

5. CFR [1997]. 29 CFR 1910.1000. Code of Federal Regulations. Washington, DC: U.S. Government Printing Office, Office of the Federal Register.

6. NIOSH [1998]. Criteria for a recommended standard: occupational exposure to metalworking fluids. Cincinnati, OH: Department of Health and Human Services, Public Health Service, Centers for Disease Control and Prevention, National Institute for Occupational Safety and Health. DHHS (NIOSH) publication number 98-102.

7. Lee SK, et al [2000]. Hypersensitivity pneumonitis caused by Fusarium napiforme in a home environment. Allergy 55 (12): 1190-1193.

8. CDC [1996]. Biopsy-confirmed hypersensitivity pneumonitis in automobile production workers exposed to metalworking fluids -- Michigan. MMWR. 45(28): 606-610.

9. Kreiss K and Cox-Ganser J [1997]. Metalworking fluid-associated hypersensitivity pneumonitis: a workshop summary. AJIM. 32:423-432.

10. Zacharisen MC, et al.[1998]. The spectrum of respiratory disease associated with exposure to metal working fluids. JOEM. 40(7):640-647.

11. Terho EO [1986]. Diagnostic criteria for farmer's lung disease. AJIM. 10:329.

12. Rossmore LA, Rossmore HW [1994]. Metalworking fluid microbiology. In: Byers J, ed. Metalworking Fluids. New York, NY: Marcel Dekker, Inc., pp. 247-271.

13. Tant CO, Bennett EO [1956]. The isolation of Pathogenic Bacteria from Used Emulsion Oils. Applied Microbiology. 4:332-338.

14. Holdom, RS [1976]. Microbial spoilage of engineering materials. Part 3: Are infected oil emulsions a health hazard to workers and to the public. Tribology International. December, pp. 271-280.

15. Tant CO, Bennett EO [1958]. The growth of aerobic bacteria in metal-cutting fluids. Applied Microbiology. 6:388-391.

16. Rossmore HW [1967]. Survival of coagulase-positive staphylococci in soluble cutting oils. Health Laboratory Science. 4:160-165.

17. Bennett, EO [1972]. The biology of metalworking fluids. Lubrication Engineering. July, pp. 237-247.

18. Hill EC [1983]. Microbial aspects of health hazards from water-based metal-working fluids. 
Tribology International. 16(3):136-140.

19. NIOSH, 1998. Hazard Evaluation and Technical Assistance report: Ford Electronics and Refrigeration Corporation, Connersville, Indiana. Cincinnati, OH: U.S. DHHS, Public Health Service, CDC; NIOSH. HETA 96-0156-2712.

20. Richerson HB, et al [1989]. Guidelines for the clinical evaluation of hypersensitivity pneumonitis. J All Clin Imm 84 (5, part 2): 839-844.

21. Newman L, Storey E, Kreiss K. 1987. Immunologic evaluation of occupational lung disease. In Rosenstock L (ed.) Occupational Medicine: state of the art reviews. Vol 2 (2):345372, Hanley and Belfus, Inc., Philadelphia, PA.

22. Fink JL, Moore VL, Barboriak JJ. 1975. Cell-mediated hypersensitivity in pigeon breeders. Int Arch Allergy Appl Immun 49:831-836.

23. McSharry C, Anderson K, Bourke SJ, and Boyd G [2002]. Takes your breath away - the immunology of allergic alveolitis. Clin and Exp Immunology 128(1):3-9.

24. McSharry C, Banham SW, Lynch PP, Boyd G [1984]. Antibody measurement in extrinsic allergic alveolitis. Eur J Respir Dis 65(4):259-65.

25. Banham SW, McSharry C, Lynch PP, Boyd $\mathrm{G}$ [1986]. Relationships between avian exposure, humoral immune response, and pigeon breeders' disease among Scottish pigeon fanciers. Thorax 41(4):274-8.

26. Schuyler M, Gott K, Cherne A [2000]. Mediators of hypersensitivity pneumonitis. J of Laboratory and Clinical Medicine. 136(1):29-38.

27. CFR [2000]. 29 CFR 1910.134. Code of Federal Regulations. Respiratory Protection. Washington, DC: U.S. Government Printing Office, Office of the Federal Register. 


\section{TABLE 1 \\ Diagnostic Criteria for Hypersensitivity Pneumonitis ${ }^{2}$ HETA 2002-155, ITP, Kokomo, Indiana}

Physician diagnosis of hypersensitivity pneumonitis

Onset of at least two pulmonary symptoms (cough, wheeze, chest tightness, shortness of breath) and one systemic symptom (fever, weight loss) after July 2001

Recurrence of pulmonary or systemic symptoms after three or more day avoidance

Restrictive pattern on spirometry not due to obesity

Impairment of pulmonary diffusing capacity less than $80 \%$ predicted

Interstitial or reticulonodular pattern on chest $\mathrm{x}$-ray or $\mathrm{CT}$

Biopsy evidence of non-caseating granulomas

Definite Case of HP: Meeting six or seven criteria.

Probable Case of HP: Meeting five criteria.

Possible Case of HP: Meeting four criteria 
TABLE 2

Description of Cases and Non-Cases

HETA 2002-155, ITP, Kokomo, Indiana

\begin{tabular}{|c|c|c|c|c|}
\hline & $\mathrm{N}$ & Age (mean) & $\#(\%)$ Male & $\#(\%)$ Current Smoker \\
\hline Non-Case & 48 & 40 & $30(63)$ & $11(23)$ \\
\hline HP Case & 6 & 44 & $6(100)$ & $0(0)$ \\
\hline
\end{tabular}

TABLE 3

Description of Exposed and Unexposed

HETA 2002-155, ITP, Kokomo, Indiana

\begin{tabular}{|c|c|c|c|c|}
\hline & $\mathrm{N}$ & Age (mean) & $\#(\%)$ Male & \# (\%) Current Smoker \\
\hline Unexposed & 11 & 41 & $5(45)$ & $2(18)$ \\
\hline Exposed & 43 & 40 & $31(72)$ & $9(21)$ \\
\hline
\end{tabular}


TABLE 4

Cytokine/Antibody Results by Case Status

HETA 2002-155, ITP, Kokomo, Indiana

\begin{tabular}{|c|c|c|c|}
\hline Cytokine/Antibody & Group & Median & $\mathrm{p}$ value $^{1}$ \\
\hline \multirow[t]{2}{*}{ IL-8 ${ }^{2}$} & non-case & 2923 & \multirow[t]{2}{*}{0.3} \\
\hline & HP case & 1398 & \\
\hline \multirow[t]{2}{*}{ IL-8 \%LPS 3} & non-case & 0 & \multirow[t]{2}{*}{0.9} \\
\hline & HP case & 0 & \\
\hline \multirow[t]{2}{*}{ IFN- $\gamma^{4}$} & non-case & 0 & \multirow[t]{2}{*}{0.2} \\
\hline & HP case & 141 & \\
\hline \multirow[t]{2}{*}{ IFN- $\gamma \% \mathrm{PHA}^{5}$} & non-case & 0 & \multirow[t]{2}{*}{0.3} \\
\hline & HP case & 4.3 & \\
\hline \multirow{2}{*}{$\begin{array}{c}\text { IFN- } \gamma \\
\text { ELISPOT }^{6}\end{array}$} & non-case & 1.0 & \multirow[t]{2}{*}{0.4} \\
\hline & HP case & 1.6 & \\
\hline \multirow{2}{*}{$\begin{array}{c}\text { IFN- } \gamma \\
\text { ELISPOT (index) }{ }^{7}\end{array}$} & non-case & 0.5 & \multirow[t]{2}{*}{0.7} \\
\hline & HP case & 1.0 & \\
\hline \multirow{2}{*}{$\begin{array}{l}\text { M. immunogenum } \\
\text { Antibody } 1\end{array}$} & non-case & 0.074 & \multirow[t]{2}{*}{0.001} \\
\hline & HP case & 0.21 & \\
\hline \multirow{2}{*}{$\begin{array}{l}\text { M. immunogenum } \\
\text { Antibody } 2\end{array}$} & non-case & 0.058 & \multirow[t]{2}{*}{0.05} \\
\hline & HP case & 0.21 & \\
\hline \multirow[t]{2}{*}{ Fusarium Antibody } & non-case & 0.035 & \multirow[t]{2}{*}{0.009} \\
\hline & HP case & 0.18 & \\
\hline
\end{tabular}

${ }^{1}$ Wilcoxon Two-sample test, two sided $;{ }^{2}$ Assay 1, IL $-8 ;{ }^{3}$ Assay 1 , IL-8 index measure; ${ }^{4}$ Assay 2, IFN- $\gamma$;

${ }^{5}$ Assay 2 , IFN- $\gamma$ index measure; ${ }^{6}$ Assay 3 , IFN- $\gamma ;{ }^{7}$ Assay 3 , IFN- $\gamma$ index measure. 
TABLE 5

Cytokine/Antibody Results by Exposure

HETA 2002-155, ITP, Kokomo, Indiana

\begin{tabular}{|c|c|c|c|}
\hline Cytokine/Antibody & Group & Median & $\mathrm{p}$ value $^{1}$ \\
\hline \multirow[t]{2}{*}{ IL-8 ${ }^{2}$} & Unexposed & 3131 & \multirow[t]{2}{*}{0.9} \\
\hline & Exposed & 2364 & \\
\hline \multirow[t]{2}{*}{ IL-8 \%LPS ${ }^{3}$} & Unexposed & 0 & \multirow[t]{2}{*}{0.02} \\
\hline & Exposed & 0.33 & \\
\hline \multirow[t]{2}{*}{ IFN- $\gamma^{4}$} & Unexposed & 0 & \multirow[t]{2}{*}{0.2} \\
\hline & Exposed & 12 & \\
\hline \multirow[t]{2}{*}{ IFN- $\gamma \% \mathrm{PHA}^{5}$} & Unexposed & 0 & \multirow[t]{2}{*}{0.2} \\
\hline & Exposed & 0.38 & \\
\hline \multirow{2}{*}{$\begin{array}{c}\text { IFN- } \gamma \\
\text { ELISPOT }^{6}\end{array}$} & Unexposed & 1.1 & \multirow[t]{2}{*}{0.8} \\
\hline & Exposed & 0.88 & \\
\hline \multirow{2}{*}{$\begin{array}{c}\text { IFN- } \gamma \\
\text { ELISPOT (index) }\end{array}$} & Unexposed & 0.25 & \multirow[t]{2}{*}{0.3} \\
\hline & Exposed & 0.5 & \\
\hline \multirow{2}{*}{$\begin{array}{l}\text { M. immunogenum } \\
\text { Antibody } 1\end{array}$} & Unexposed & 0.057 & \multirow[t]{2}{*}{0.03} \\
\hline & Exposed & 0.10 & \\
\hline \multirow{2}{*}{$\begin{array}{l}\text { M. immunogenum } \\
\text { Antibody } 2\end{array}$} & Unexposed & 0.035 & \multirow[t]{2}{*}{0.008} \\
\hline & Exposed & 0.077 & \\
\hline \multirow[t]{2}{*}{ Fusarium Antibody } & Unexposed & 0.02 & \multirow[t]{2}{*}{0.2} \\
\hline & Exposed & 0.04 & \\
\hline
\end{tabular}

${ }^{1}$ Wilcoxon Two-sample test, two sided ${ }^{2}$ Assay 1, IL- $8 ;{ }^{3}$ Assay 1 , IL-8 index measure; ${ }^{4}$ Assay 2 , IFN- $\gamma$;

${ }^{5}$ Assay 2 , IFN- $\gamma$ index measure; ${ }^{6}$ Assay 3 , IFN- $\gamma ;{ }^{7}$ Assay 3 , IFN- $\gamma$ index measure. 


\section{APPENDIX 1 - Laboratory Methods}

Our analyses for cell-mediated immunity to M. immunogenum was evaluated using 3 distinct assay systems. For the purpose of this report, the three assays will be referred to as Assays 1-3. A laboratory at the University of Michigan performed Assay 1 by measuring interferon gamma (IFN- $\gamma$ ), tumor necrosis factor alpha (TNF- $\alpha$ ), and interleukin 8 (IL-8) secretion in whole blood cultures stimulated with purified protein derivative prepared from $M$. immunogenum culture filtrate. For comparisons purposes, stimulation was also performed in Assay 1 with a standard purified protein derivative from $M$. tuberculosis, lipopolysaccharide (LPS) (component of endotoxin), and the vehicle used for the preparation (used as control). Assay 1 may be adaptable to field studies; however, it is only suitable for short-term cultures, and thus may lack the sensitivity of other approaches. For this reason, additional assays were performed based on purification of PBMCs from the whole blood. These additional studies, performed by NIOSH Analytical Services Branch, Health Effects Laboratory Division (HELD), included both longer-term cultures optimized for both antigen dose and kinetics to assess secretion of IFN- $\gamma$ (Assay 2), and IFN- $\gamma$ ELISPOT to assess numbers of circulating antigen-specific lymphocytes in study subjects (Assay 3). IFN- $\gamma$ secretion determined by Assay 2 was performed at three different dilutions of antigen preparation (1:10,1:20, and 1:100). The data for the 1:20 dilutions correlated well with data for the 1:10 dilution $(r=0.84)$ and less well with data from the 1:100 dilution $(r=0.37)$. Data for the 1:20 dilution are presented in this report as representative data for this testing methodology.

To control for the number of viable cytokine-producing cells (mononuclear cells) in the blood samples for assays 1 and 2, the secretion of cytokines resulting from stimulation by $M$. immunogenum was expressed as a percentage of the cytokine secreted after stimulation from a known strong stimulant. This substance in Assay 1 was LPS (endotoxin), and in assays 2 and 3 was phytohemagglutinin (PHA). The equation used to calculate the '\% LPS' (or \%PHA) is: [(cytokine stimulated by antigen - cytokine stimulated control) / (cytokine stimulated by LPS - cytokine stimulated by control)] * 100 . $^{+}$For the ELISPOT (assay 3), the index measure used in the evaluation was the difference between antigenstimulated result and the result from the negative control.

\section{Assay 1 - University of Michigan, Whole Blood Assay Protocol to measure the hypersensitivity exposure to metalworking fluids from Kokomo, Indiana.}

The PPD prepared from M. immunogenum (MI-PPD; see below) antigen preparation was prepared at ten times concentration, and 110 microliter $(\mu \mathrm{L})$ were added to one $\mathrm{mL}$ of whole blood. Enough stimulant was prepared for at least 40 participants. The blood and the MI-PPD were combined in the following order. The MI-PPD stock was 31 milligram $(\mathrm{mg}) / \mathrm{mL}$, and stimulation was performed at $0.248 \mu \mathrm{g} / \mathrm{mL}$. The stock was diluted 1/100 (990 $\mu \mathrm{L}$ contol vehicle (RPMI) $+10 \mu \mathrm{L}$ MI-PPD). Forty $\mu \mathrm{L}$ of the above dilution was added to five $\mathrm{mL}$ of RPMI for a final concentration of $2.48 \mu \mathrm{g} / \mathrm{mL}$. The lipopolysaccharide (LPS) antigen was prepared as follows. The stock was $100 \mu \mathrm{g} / \mathrm{mL}$ and we stimulated at 100 nanogram

+ Mazurek GH, et al. [2001]. Comparison of a whole-blood interferon $\gamma$ assay with tuberculin skin testing for detecting latent Mycobacterium tuberculosis infection. JAMA 286(14):1740-1747. 
(ng) $/ \mathrm{mL}(50 \mu \mathrm{L}$ of stock was added to five $\mathrm{mL}$ RPMI for a final concentration of $1000 \mathrm{ng} / \mathrm{mL}$. After adding blood, the tubes were placed on the rotator in the incubator $\left(37^{\circ} \mathrm{C}\right)$ for 20 hours. At the end of 20 hours, the tubes were spun at $2000 \mathrm{x}$ g for three minutes, and the plasma was drawn off and frozen at $-70^{\circ} \mathrm{C}$. Enzyme linked immunosorbent assay (ELISA) was used to analyze for TNF- $\alpha$, IFN- $\gamma$, and IL-8.

\section{Assays 2 and 3, NIOSH, HELD}

Preparation of M. immunogenum PPD: M. immunogenum (MI) was obtained from the American Type Culture Collection (ATCC), Manassas, VA (\#700506). This isolate was deposited by Dr. Richard Wallace and has previously been implicated as causing metalworking fluid-related hypersensitivity pneumonitis. ${ }^{++}$Purified protein derivative from MI (MI-PPD) was prepared in a fashion similar to that described by Landi. ${ }^{++}$Briefly, MI was cultured in Middlebrook 7H9 broth supplemented with OADC for 3 weeks at $37^{\circ} \mathrm{C}$. At this point, growth was heavy with a large amount of precipitated material present in cultures. Cultures were sterilized by autoclaving for 15 minutes. Culture supernatants were obtained by centrifugation $\left(20,000 \mathrm{x} \mathrm{g}, 4^{\circ} \mathrm{C}, 1\right.$ hour$)$. Protein was precipitated from culture supernatants using saturated ammonium sulfate. Precipitate was obtained by centrifugation $\left(20,000 \mathrm{xg}, 4^{\circ} \mathrm{C}, 1 \mathrm{hr}\right)$ and redissolved in a minimum volume of phosphate-buffered saline (PBS). This material was dialyzed against four 20-fold volumes of PBS at $4^{\circ} \mathrm{C}$ over the next 48 hour. The dialysate was removed, clarified by centrifugation $\left(20,000 \mathrm{x} \mathrm{g}, 4^{\circ} \mathrm{C}, 4\right.$ hours), passed through a $0.45 \mu \mathrm{m}$ filter, aliquoted, and stored frozen at $-70^{\circ} \mathrm{C}$. The resulting MI-PPD preparation was sterile, had a protein concentration of $31 \mathrm{mg} / \mathrm{ml}$ by Lowry assay, and an endotoxin concentration of $1.3 \mathrm{ng} / \mathrm{mL}$ by limulus amoebocyte lysate (LAL) assay. The optimal dilution of the MI-PPD preparation for stimulating interferon (IFN)-gamma secretion by a tuberculin positive volunteer's peripheral blood mononuclear cells (PBMC) using the assay described below was 1:20.

Preparation of cell populations: Blood was obtained by venipuncture and collected into heparinized tubes. Samples were shipped to the laboratory by overnight express at ambient temperature. PBMC were prepared by centrifugation over sodium diatrizoate/Ficoll gradients(Isolymph, Gallard Schlesinger, Carle Place, NY).

Interferon-gamma secretion assays: Cultures were performed in 96-well round-bottomed microtiter plates using RPMI-1640 tissue culture medium supplemented with 25 mM HEPES, 2 mM L-glutamine, 100 units $/ \mathrm{mL}$ penicillin, $0.1 \mathrm{mg} / \mathrm{mL}$ streptomycin, $5 \%$ fetal calf serum, and $5 \%$ human AB serum (CRPMI). $2 \times 10^{5}$ PBMC in a volume of 200:1 culture medium per well were cultured with CRPMI alone (negative

${ }^{++}$Moore JS, Christensen M, Wilson RW, Wallace RJ Jr, Zhang Y, Nash DR, Shelton B. Mycobacterial contamination of metalworking fluids: involvement of a possible new taxon of rapidly growing mycobacteria. Amer Ind Hyg Assoc J 2000 Mar-Apr;61(2):205-13.

${ }^{+++}$Landi S. Production and standardization of tuberculin. In: Kubica GP, Wayne LG, eds. The mycobacteria - a sourcebook. Part A. New York: Marcel Dekker, Inc., ISBN \#0-8247-7009-9, pp 505$535,1984$. 
control), phytohemagglutinin-P (PHA) $5 \mu \mathrm{g} / \mathrm{ml}$ (positive control), purified protein derivative (PPD) 20 $\mu \mathrm{g} / \mathrm{ml}$ (Accurate Chemical \& Scientific Co., Westbury, NY), or PPD prepared from M. immunogenum (MI-PPD; see above) diluted to a final concentration of 1:10, 1:20, or 1:100. Cultures were performed at $37{ }^{\circ} \mathrm{C}$ and $5 \%$ carbon dioxide $\left(\mathrm{CO}_{2}\right)$ for 5 days, an interval previously documented to be optimal for determination of PPD-induced IFN-gamma secretion by PBMC from tuberculin positive individuals (data not shown). After 5 days, conditioned culture supernatants were obtained and saved frozen at $-70^{\circ} \mathrm{C}$ until assayed for IFN-gamma content by ELISA (Interferon Gamma Duoset, R \& D Systems, Minneapolis, $\mathrm{MN})$. The data for the 1:20 dilution are presented here; these data correlated with data for the 1:10 dilution $(\mathrm{r}=0.84)$ and less well with data from the $1: 100$ dilution $(\mathrm{r}=0.37)$.

Interferon-gamma ELISPOT assays: To perform ELISPOT assays, 96-well PVDF membrane-bottomed plates (MAIPS4510, Millipore, Bedford, MA) were coated overnight with $50 \mathrm{uL} /$ well of $10 \mathrm{ug} / \mathrm{mL}$ solution of anti-human IFN-gamma monoclonal antibody (clone 1-D1K; Mabtech Inc., Cincinnati, OH) in carbonate buffer, $\mathrm{pH}$ 9.6. After washing and blocking with CRPMI, cultures were performed in CRPMI alone (negative control), PHA-P $5 \mu \mathrm{gml}$ (positive control), purified protein derivative (PPD) 20 $\mu \mathrm{g} / \mathrm{mL}$ (Accurate Chemical \& Scientific Co., Westbury, NY), or MI-PPD diluted to a final concentration of 1:20. $5 \times 10^{4}$ cells were added to cultures performed with PHA-P; all other cultures were performed with $2 \times 10^{5}$ cells. Plates were incubated at $37^{\circ} \mathrm{C}, 5 \% \mathrm{CO}_{2}$ overnight. To visualize spots, plates were incubated with the following reagents with appropriate washing steps between incubations: biotinylated anti-human IFN-gamma monoclonal antibody $1 \mu \mathrm{g} / \mathrm{mL}$ (clone 7-B6-1, Mabtech Inc., Cincinnati, OH), Vectastain AB reagent (Vectastain ABC Elite kit, Vector Laboratories, Burlingame, CA), and Vector VIP peroxidase substrate (Vector Laboratories, Burlingame, CA). Plates were washed with water, dried, and spots counted using a dissecting microscope.

\section{Antibody Studies, NIOSH, HELD}

Preparation of Antigen 1: This antigen originated from a pure isolate of M. immunogenum from the HELD laboratory; this antigen preparation was a sonicate, which contains both cell-associated and secreted products. To create the sonicate, the isolate was suspended in saline as a $10 \%$ volume/volume suspension. The bacterial suspensions were sonicated for one minute using a Branson Model 350 sonifier set at $40 \%$ output, $50 \%$ duty cycle pulse. The sonicates were clarified by centrifugation at $3500 \mathrm{rpm}$ for 20 minutes, and the supernatant fluid was recovered, stored at $-20^{\circ} \mathrm{C}$, and used as the source of antigen. The protein content of bacterial sonicate was determined using a modified Lowry method (BioRad) according to the manufacturer's recommendations. The bacterial sonicates were diluted with saline to comparable protein levels and tested by both precipitin and western blotting techniques with a commercial antisera to mycobacteria (Bio-Genesis) and found antigenically identical. Based on these results, immunoassays were carried out using a sonicate of the isolates that yielded the largest volume of antigen extract.

Preparation of Antigen 2: The PPD created as described above, which is a culture filtrate enriched for secreted products, was used as Antigen 2. 
A direct enzyme linked immunosorbent assay (ELISA) for antibodies to $M$. immunogenum was developed using the procedures described by Voller and Bidwell (Manual of Clinical Immunology, 4th Edition, ASM Press, Washington, D.C.). ELISA plates were coated with the M. immungenum extract (3 to $5 \mathrm{ug}$ protein $/ \mathrm{mL}$ ) in carbonate coating buffer overnight at $4^{\circ} \mathrm{C}$, blocked with $1 \%$ human serum albumin, and stored at $4{ }^{\circ} \mathrm{C}$ until used but for no more than one week. The subject sera were initially tested in duplicate at a 1:80 dilution, and antibody binding was detected using peroxidase labeled antihuman immunoglobulins (Sigma) and developed with TMB substrate. Appropriate positive and negative controls were performed with each plate, including (as a positive control for $M$. immunogenum) rabbit antisera to mycobacterial antigen, a primary and a secondard antibody control, and an antigen blank. To determine the background, or non-specific binding levels, a set of sera were pre-incubated with soluble antigen and then assayed as usual. Results for all ELISA were reported in absorbency units.

Preparation ofFusarium antigen and ELISA procedure: Antigen extracts of a Fusarium sp isolated from ITP were prepared from colonies grown on malt extract agar (MEA). The mycelium and spores were washed from the from the culture plates using sterile saline containing $0.1 \%$ Tween 80 , disrupted by sonication using a Branson Model 350 sonicator, and the supernatant fluid recovered after centrifugation $3500 \mathrm{rpm}$ for 20 minutes. The extract was dialyzed against carbonate coupling buffer ( $\mathrm{pH} 9.6)$ and the total protein content determined by a modified Lowry (Bio-Rad Laboratories, Inc. Hercules, CA) according to the manufacturer's recommendations. The samples stored at $-20 \mathrm{C}$ until used.

A direct ELISA for antibodies to fungal extracts was developed using procedures described for the mycobacterial isolate. Briefly, ELISA plates were coated with the fungal extract (3 to $5 \mathrm{ug}$ protein $/ \mathrm{ml}$ ), and blocked with $1 \%$ powdered milk. The plates were reacted sequentially with sera from the subjects diluted 1:1000, and peroxidase labeled anti-human immunoglobulins. Peroxidase activity was detected using tetramethyl benezidine (TMB) substrate (Sigma Immunochemicals, St Louis, MO). Each plate included a saline control, a negative serum control (from an individual with no known exposure), and a positive control (serum from an individual with antibodies).

ELISA results are reported in term of optical density values. 
APPENDIX 2 - Data

Table Appendix 2A - IL-8 Concentrations from Assay 1

HETA 2002-155, ITP, Kokomo, Indiana

\begin{tabular}{|c|c|c|c|c|}
\hline ID & $\mathrm{MI}^{1}$ & RPMI $^{2}$ & LPS $^{3}$ & MI \% LPS \\
\hline 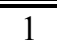 & 2786 & 6484 & 34533 & 0 \\
\hline 2 & 2173 & 1204 & 24078 & 4 \\
\hline 3 & 11001 & 7092 & 30274 & 17 \\
\hline 4 & 1398 & 1611 & 29371 & 0 \\
\hline 5 & 7238 & 3473 & 24523 & 18 \\
\hline 6 & 809 & 1000 & 17372 & 0 \\
\hline 7 & 2135 & 2184 & 29092 & 0 \\
\hline 8 & 587 & 384 & 29011 & 1 \\
\hline 9 & 6295 & 3983 & 29908 & 9 \\
\hline 10 & 1559 & 1294 & 28378 & 1 \\
\hline 11 & 9468 & 8934 & 32284 & 2 \\
\hline 12 & 5186 & 13907 & 34451 & 0 \\
\hline 14 & 557 & 480 & 8573 & 1 \\
\hline 15 & 3624 & 4914 & 43202 & 0 \\
\hline 16 & 4631 & 7184 & 23244 & 0 \\
\hline 17 & 5808 & 10776 & 29416 & 0 \\
\hline 18 & 15213 & 8916 & 31155 & 28 \\
\hline 19 & 1292 & 835 & 26912 & 2 \\
\hline 20 & 3763 & 3632 & 24720 & 1 \\
\hline 21 & 86 & 2377 & 24395 & 0 \\
\hline 22 & 425 & 344 & 24624 & 0 \\
\hline 23 & 11390 & 6198 & 42728 & 14 \\
\hline 24 & 9139 & 9694 & 61556 & 0 \\
\hline 25 & 1382 & 912 & 28223 & 2 \\
\hline 26 & 2364 & 2838 & 33043 & 0 \\
\hline 27 & 3131 & 4109 & 35452 & 0 \\
\hline 28 & 1157 & 1343 & 20722 & 0 \\
\hline 29 & 9866 & 15773 & 33948 & 0 \\
\hline 30 & 1770 & 3316 & 32002 & 0 \\
\hline 31 & 3831 & 5747 & 6544 & 0 \\
\hline 32 & 3916 & 5600 & 66735 & 0 \\
\hline 33 & 2687 & 1103 & 49046 & 3 \\
\hline 34 & 15158 & 20615 & 50901 & 0 \\
\hline 35 & 1503 & 18490 & 75047 & 0 \\
\hline 36 & 18218 & 14012 & 42395 & 15 \\
\hline
\end{tabular}




\begin{tabular}{|c|c|c|c|c|}
\hline ID & MI $^{1}$ & RPMI $^{2}$ & LPS $^{3}$ & MI \% LPS \\
\hline \hline 37 & 1887 & 1443 & 23385 & 2 \\
\hline 38 & 2923 & 4949 & 42059 & 0 \\
\hline 39 & 2393 & 2221 & 49601 & 0 \\
\hline $40^{5}$ & 4541 & $\cdot$ & $\cdot$ & 0 \\
\hline 41 & 1265 & 1237 & 40578 & 1 \\
\hline 42 & 1407 & 1124 & 29151 & 0 \\
\hline 43 & 1855 & 10659 & 23243 & 7 \\
\hline 44 & 1838 & 315 & 21078 & 0 \\
\hline 45 & 10177 & 10535 & 30163 & 0 \\
\hline 46 & 1737 & 7497 & 33376 & 0 \\
\hline 47 & 159 & 297 & 12303 & \\
\hline
\end{tabular}

${ }^{1} \mathrm{IL}-8$ concentration $(\mathrm{pg} / \mathrm{mL})$ after stimulation by M. immunogenum

${ }^{2}$ IL-8 concentration ( $\mathrm{pg} / \mathrm{mL}$ ) after stimulation by control vehicle

${ }^{3} \mathrm{IL}-8$ concentration $(\mathrm{pg} / \mathrm{mL})$ after stimulation by lipopolysaccharide

${ }^{4}$ Calculated using [(IL8 antigen - IL8 RPMI) / (IL8 LPS - IL8 RPMI)]* 100; negative numbers assigned a value of 0 .

${ }^{5}$ Insufficient sample to perform complete test 
Table Appendix 2B - IFN- $\gamma$ Concentrations from Assay 2

HETA 2002-155, ITP, Kokomo, Indiana

\begin{tabular}{|c|c|c|c|c|}
\hline ID & Assay $2 \mathrm{MI}^{1}$ & Assay 2 Control $^{2}$ & $\mathrm{PHA}^{3}$ & MI \% $\mathrm{PHA}^{4}$ \\
\hline 1 & 0 & 0 & 730 & 0 \\
\hline 2 & 16 & 0 & 590 & 2.71 \\
\hline 3 & 0 & 0 & 560 & 0 \\
\hline 4 & 276 & 0 & 2830 & 9.75 \\
\hline 5 & 0 & 0 & 780 & 0 \\
\hline 6 & 200 & 0 & 820 & 24.39 \\
\hline 7 & 204 & 25 & 1755 & 10.35 \\
\hline 8 & 900 & 0 & 3885 & 23.17 \\
\hline 9 & 696 & 0 & 3825 & 18.20 \\
\hline 10 & 984 & 0 & 3095 & 31.79 \\
\hline 11 & 504 & 82 & 535 & 93.16 \\
\hline 12 & 0 & 0 & 3885 & 0 \\
\hline 14 & 12 & 0 & 415 & 2.89 \\
\hline $15^{5}$ & & & & \\
\hline 16 & 373 & 0 & 1075 & 34.70 \\
\hline 17 & 137 & 0 & 598 & 22.91 \\
\hline 18 & 20 & 0 & 1355 & 1.48 \\
\hline 19 & 172 & 0 & 1243 & 13.84 \\
\hline 20 & 4 & 0 & 1120 & 0.36 \\
\hline 21 & 54 & 0 & 3795 & 1.42 \\
\hline 22 & 0 & 0 & 1552 & 0 \\
\hline 23 & 0 & 0 & 76900 & 0 \\
\hline 24 & 0 & 0 & 2793 & 0 \\
\hline 25 & 0 & 0 & 2898 & 0 \\
\hline 26 & 0 & 0 & 9820 & 0 \\
\hline 27 & 0 & 0 & 1728 & 0 \\
\hline 28 & 0 & 0 & 2545 & 0 \\
\hline 29 & 12 & 0 & 3150 & 0.38 \\
\hline 30 & 0 & 0 & 2798 & 0 \\
\hline 31 & 154 & 0 & 7650 & 2.01 \\
\hline 32 & 0 & 0 & 2410 & 0 \\
\hline 33 & 0 & 0 & 2833 & 0 \\
\hline 34 & 0 & 0 & 2298 & 0 \\
\hline 35 & 44 & 0 & 2475 & 1.78 \\
\hline 36 & 302 & 0 & 4370 & 6.91 \\
\hline $37^{5}$ & & & & \\
\hline
\end{tabular}




\begin{tabular}{|c|c|c|c|c|}
\hline ID & Assay 2 MI $^{1}$ & Assay 2 Control & MI \% PHA \\
\hline \hline 38 & 0 & 0 & 2760 & 0 \\
\hline 39 & 23 & 0 & 3808 & 0.60 \\
\hline 40 & 0 & 0 & 4735 & 0 \\
\hline 41 & 0 & 0 & 2488 & 0 \\
\hline 42 & 0 & 0 & 2610 & 0 \\
\hline 43 & 0 & 0 & 1893 & 0 \\
\hline 44 & 0 & 0 & 2958 & 0 \\
\hline 45 & 0 & 0 & 143 & 0 \\
\hline 46 & 0 & 0 & 3815 & 0 \\
\hline 47 & 0 & 0 & 555 & 0 \\
\hline 48 & 202 & 0 & 1868 & 2.83 \\
\hline 49 & 113 & 0 & 3995 & 6.20 \\
\hline 50 & 25 & 0 & 403 & 0.57 \\
\hline 51 & 28 & 0 & 4915 & 0 \\
\hline 52 & 0 & 0 & 970 & 1.60 \\
\hline 53 & 82 & 0 & 5130 & 0.26 \\
\hline 54 & 13 & 0 & 5000 & 0 \\
\hline 55 & 0 & 0 & 6100 & PH $^{3}$ \\
\hline
\end{tabular}

${ }^{1}$ IFN- $\gamma$ concentration $(\mathrm{pg} / \mathrm{mL})$ after stimulation by $M$. immunogenum

${ }^{2}$ IFN- $\gamma$ concentration $(\mathrm{pg} / \mathrm{mL})$ after stimulation by control vehicle

${ }^{3}$ IFN- $\gamma$ concentration $(\mathrm{pg} / \mathrm{mL})$ after stimulation by PHA

${ }^{4}$ Calculated using [(IFN- $\gamma$ antigen - IFN- $\gamma$ RPMI) / (IFN- $\gamma$ LPS - IFN- $\gamma$ RPMI) ${ }^{*} 100$; negative numbers assigned a value of 0 .

${ }^{5}$ Insufficient sample to perform complete test 
Table Appendix 2C - ELISPOT (Assay 3)

HETA 2002-155, ITP, Kokomo, Indiana

\begin{tabular}{|c|c|c|c|c|}
\hline ID & $\mathrm{MI}^{1}$ & Control $^{2}$ & $\mathrm{PHA}^{3}$ & Index $^{4}$ \\
\hline 1 & 0.5 & 0.5 & 20 & 0 \\
\hline 2 & 1.5 & 0.5 & 137 & 1 \\
\hline 3 & 2.25 & 0 & 74 & 2.25 \\
\hline 4 & 8 & 0.25 & 323 & 7.75 \\
\hline 5 & 4.25 & 0.25 & 161 & 4 \\
\hline 6 & 2.5 & 0.75 & 378 & 1.75 \\
\hline 7 & 0.25 & 0 & 70 & 0.25 \\
\hline 8 & 5.25 & 0 & 306 & 5.25 \\
\hline 9 & 2 & 0 & 130 & 2 \\
\hline 10 & 6.25 & 0.25 & 374 & 6 \\
\hline 11 & 0.25 & 0 & 445 & 0.25 \\
\hline 12 & 3.5 & 0.75 & 157 & 2.75 \\
\hline \multicolumn{5}{|l|}{$14^{5}$} \\
\hline 15 & 0 & 0 & 161 & 0 \\
\hline 16 & 1.25 & 0.25 & 195 & 1 \\
\hline 17 & 2.25 & 0.25 & 393 & 2 \\
\hline 18 & 1 & 0.5 & 119 & 0.5 \\
\hline 19 & 0 & 0.25 & 198 & 0 \\
\hline 20 & 0.75 & 1.25 & 181 & 0 \\
\hline 21 & 2 & 0.25 & 442 & 1.75 \\
\hline 22 & 1.25 & 0.5 & 539 & 0.75 \\
\hline 23 & 1 & 0.75 & 324 & 0.25 \\
\hline 24 & 1.5 & 0 & 230 & 1.5 \\
\hline 25 & 0.5 & 0 & 378 & 0.5 \\
\hline 26 & 0.25 & 0 & 220 & 0.25 \\
\hline 27 & 0 & 0 & 166 & 0 \\
\hline 28 & 0 & 0 & 55 & 0 \\
\hline 29 & 0 & 0 & 56 & 0 \\
\hline 30 & 0 & 0 & 375 & 0 \\
\hline 31 & 1 & 0 & 320 & 1 \\
\hline 32 & 0.25 & 0 & 53 & 0.25 \\
\hline 33 & 0 & 0 & 28 & 0 \\
\hline 34 & 0.5 & 0 & 30 & $\overline{0.5}$ \\
\hline 35 & 1.25 & 0 & 615 & 1.25 \\
\hline 36 & 4.75 & 0 & 265 & 4.75 \\
\hline 37 & 0.25 & 0 & 122 & 0.25 \\
\hline
\end{tabular}




\begin{tabular}{|c|c|c|c|c|}
\hline ID & MI $^{1}$ & Control $^{2}$ & PHA $^{3}$ & Index $^{4}$ \\
\hline \hline $38^{5}$ & & & & 0 \\
\hline 39 & 0 & 0 & 175 & 0.25 \\
\hline $40^{5}$ & & & & 1 \\
\hline 41 & 0.25 & 0 & 98 & 1.25 \\
\hline 42 & 1 & 0 & 177 & 1 \\
\hline 43 & 1.25 & 0 & 166 & 0.5 \\
\hline 44 & 1 & 0 & 129 & 0 \\
\hline 45 & 0.75 & 0.25 & 653 & 0 \\
\hline 46 & 117.25 & 195.25 & 197 & 0.5 \\
\hline 47 & 0.5 & 0.5 & 141 & 0.25 \\
\hline 48 & 1 & 0.5 & 106 & 0.25 \\
\hline 49 & 1.25 & 1 & 78 & 0.25 \\
\hline 50 & 0.25 & 0 & 249 & 2 \\
\hline 51 & 0.5 & 0.25 & 142 & 0.25 \\
\hline 52 & 2 & 0 & 95 & 0.25 \\
\hline 53 & 0.75 & 0.5 & 100 & 0.5 \\
\hline 54 & 0.25 & 0 & 606 & \\
\hline 55 & 0.5 & 0.25 & & \\
\hline
\end{tabular}

${ }^{1}$ Spots per $10^{5}$ peripheral blood mononuclear cells after stimulation by M. immunogenum

${ }^{2}$ Spots per $10^{5}$ peripheral blood mononuclear cells after stimulation by control vehicle

${ }^{3}$ Spots per $10^{5}$ peripheral blood mononuclear cells after stimulation by PHA

${ }^{4}$ MI minus control.

${ }^{5}$ Not evaluable 
Table Appendix 2D - Antibody (absorbency units) HETA 2002-155, ITP, Kokomo, Indiana

\begin{tabular}{|c|c|c|c|}
\hline ID & MI Antibody $1^{1}$ & MI Antibody $2^{2}$ & Fusarium Antibody ${ }^{3}$ \\
\hline 1 & .035 & .046 & 0.124 \\
\hline 2 & .015 & .036 & 0.0195 \\
\hline 3 & .196 & .077 & 0.0345 \\
\hline 4 & .345 & .255 & 0.043 \\
\hline 5 & .102 & .055 & 0.009 \\
\hline 6 & .199 & .209 & 0.2865 \\
\hline 7 & .022 & .028 & 0.013 \\
\hline 8 & .129 & .059 & 0.125 \\
\hline 9 & .175 & .125 & 0.0575 \\
\hline 10 & .007 & .020 & 0.011 \\
\hline 11 & .062 & .019 & 0.326 \\
\hline 12 & .067 & .030 & 0.019 \\
\hline 14 & .040 & .134 & 0.062 \\
\hline 15 & .041 & .026 & 0.027 \\
\hline 16 & .078 & .062 & 0.032 \\
\hline 17 & .020 & .013 & 0.0595 \\
\hline 18 & .023 & .085 & 0.034 \\
\hline 19 & .057 & .050 & 0.01 \\
\hline 20 & .140 & .048 & 0.2145 \\
\hline 21 & .081 & .056 & 0.0395 \\
\hline 22 & .977 & .627 & 0.218 \\
\hline 23 & .091 & .039 & 0.0605 \\
\hline 24 & .181 & .238 & 0.07 \\
\hline 25 & .137 & .055 & 0.0775 \\
\hline 26 & .036 & .040 & 0.0105 \\
\hline 27 & .041 & .021 & 0.0355 \\
\hline 28 & .058 & .083 & 0.022 \\
\hline 29 & .056 & .399 & 0.0125 \\
\hline 30 & .432 & .091 & 0.044 \\
\hline 31 & .036 & .027 & 0.0255 \\
\hline 32 & .093 & .093 & 0.0125 \\
\hline 33 & .588 & .214 & 0.3695 \\
\hline 34 & .112 & .082 & 0.039 \\
\hline 35 & .304 & .221 & 0.1405 \\
\hline 36 & .205 & .061 & 0.1495 \\
\hline 37 & .116 & .116 & 0.034 \\
\hline
\end{tabular}




\begin{tabular}{|c|c|c|c|}
\hline ID & MI Antibody $1^{1}$ & MI Antibody $2^{2}$ & ${\text { Fusarium } \text { Antibody }^{3}}^{\text {M }}$ \\
\hline \hline 38 & .057 & .079 & 0.1215 \\
\hline 39 & .200 & .099 & 0.0615 \\
\hline 40 & .062 & .015 & 0.021 \\
\hline 41 & .102 & .070 & 0.0165 \\
\hline 42 & .201 & .086 & 0.059 \\
\hline 43 & .035 & .243 & 0.0105 \\
\hline 44 & .069 & .037 & 0.0405 \\
\hline 45 & .078 & .031 & 0.014 \\
\hline 46 & .024 & .029 & 0.036 \\
\hline 47 & .184 & .222 & 0.2145 \\
\hline 48 & .123 & .054 & 0.018 \\
\hline 49 & .090 & .035 & 0.112 \\
\hline 50 & .044 & .035 & 0.014 \\
\hline 51 & .068 & .096 & 0.0105 \\
\hline 52 & .024 & .061 & 0.0135 \\
\hline 53 & .218 & .037 & 0.051 \\
\hline 54 & .307 & .099 & 0.056 \\
\hline 55 & .123 & .142 & 0.217 \\
\hline
\end{tabular}

${ }^{1}$ Sonicate of $M$. immunogenum

${ }^{2}$ PPD preparation of $M$. immunogenum

${ }^{3}$ Fusarium Antigen, 1/5000 dilution 
To receive NIOSH documents or information about occupational safety and health topics contact NIOSH at:

\author{
1-800-35-NIOSH (356-4674) \\ Fax: 1-513-533-8573 \\ E-mail: pubstaff@cdc.gov \\ or visit the NIOSH web site at: \\ www.cdc.gov/niosh
}

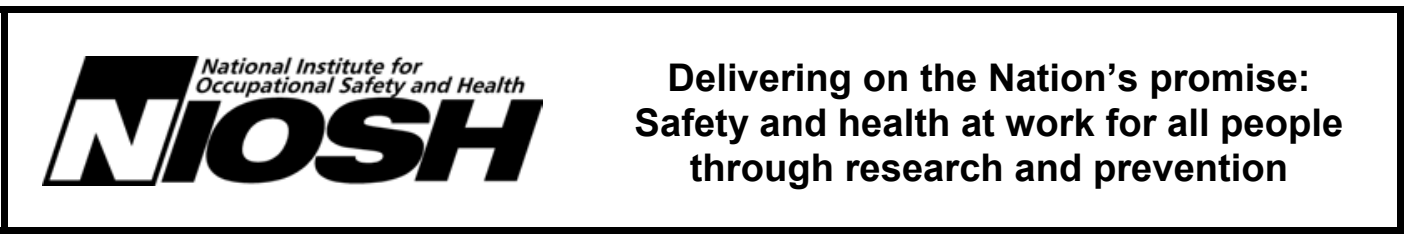


SAFER • HEALTHIER • PEOPLE ${ }^{\text {TM }}$ SAFER • HEALTHIER • PEOPLE ${ }^{\mathrm{TM}}$ 